\title{
Supplementary Information for: Aircraft Observations of Aerosol in the Manaus Urban Plume and Surrounding Tropical Forest during GoAmazon 2014/15
}

John E. Shilling ${ }^{1}$, Mikhail S. Pekour ${ }^{1}$, Edward C. Fortner ${ }^{2}$, Paulo Artaxo ${ }^{3}$, Suzane de Sá ${ }^{4}$, John M. Hubbe ${ }^{1}$, 5 Karla M. Longo ${ }^{5}$, Luiz A.T. Machado ${ }^{6}$, Scot T. Martin ${ }^{4,7}$, Stephen R. Springston ${ }^{8}$, Jason Tomlinson ${ }^{1}$, Jian Wang 8

\footnotetext{
${ }^{1}$ Atmospheric Sciences and Global Change Division, Pacific Northwest National Laboratory, Richland, Washington, USA ${ }^{2}$ Center for Aerosol and Cloud Chemistry, Aerodyne Research, Billerica, Massachusetts, USA
}

10 Institute of Physics, University of Sao Paulo, Sao Paulo, Brazil

${ }^{4}$ John A. Paulson School of Engineering and Applied Sciences and Department of Earth and Planetary Sciences, Harvard University, Cambridge, Massachusetts, USA

${ }^{5}$ University Space Research Association/Goddard Earth Sciences Technology and Research (USRA/GESTAR), National Aeronautics and Space Administration, Goddard Space Flight Center, Columbia, Maryland, USA

$15{ }^{6}$ Centro de Previsao de Tempo e Estudos Climaticos - Instituto Nacional de Pesquisas Espaciais, Sao Jose dos Campos, Brazil ${ }^{7}$ Department of Earth and Planetary Sciences, Harvard University, Cambridge, Massachusetts, USA

${ }^{8}$ Environmental and Climate Sciences Department, Brookhaven National Laboratory, Upton, New York, USA

Correspondence to: John E. Shilling (john.shilling@pnnl.gov) 


\section{S1 Calculation of $\Delta \mathrm{org} / \Delta \mathrm{CO}$}

As described in the main manuscript text, we find no change in $\Delta \mathrm{org} / \Delta \mathrm{CO}$ as the Manaus plume is transported downwind and ages, despite other metrics, such as the aerosol carbon oxidation state increasing, indicating plume aging. In an effort to ensure this observation is robust, we calculated $\Delta \mathrm{org} / \Delta \mathrm{CO}$ in several different ways. In order to test the sensitivity of the calculation

5 to the chosen background organic aerosol and $\mathrm{CO}$ concentrations, we also vary these quantities. In total, we calculated $\Delta \mathrm{org} / \Delta \mathrm{CO} 16$ different ways, using a combination of different calculations and backgrounds. The results of five of these calculations, which span a range of calculation methods and backgrounds, are shown in Figure S1. As seen in Figure S1, none of these methods shows a trend in $\Delta \mathrm{org} / \Delta \mathrm{CO}$ with plume aging. We next describe the details of the calculation methods, the different background values of org and $\mathrm{CO}$ that were used in calculations, and the rationale for choosing these backgrounds

10 and end with some general conclusions regarding the calculations.

1) Method 1 (M1 on Figure S1) - The AMS-measured organic aerosol concentration was plotted against the measured CO concentration. All data for each flight leg perpendicular to the wind direction were included. Background values of org and $\mathrm{CO}$ were not subtracted from the data. $\Delta \mathrm{org} / \Delta \mathrm{CO}$ was calculated as the slope of the linear regression that was not forced through the origin.

15 2) Method 2 (M2) - Uses the same methodology as M1 except a background value of org $=0.33 \mu \mathrm{g} / \mathrm{m}^{3}$ and $\mathrm{CO}=80.5 \mathrm{ppbv}$ were subtracted from each OA and CO measurement. The linear regression was not forced through the origin.

3) Method 3 (M3) - $\Delta \mathrm{org} / \Delta \mathrm{CO}$ calculated using the arithmetic mean as: $\frac{\Delta \text { org }}{\Delta C O}=\frac{\left(\overline{\text { org }}_{\text {plume }}-\overline{\text { org }}_{\text {background }}\right)}{\left(\overline{C O}_{\text {plume }}-\overline{C O}_{\text {background }}\right)}$. Background values of $\mathrm{CO}$ and org are different for each leg and chosen as the mean of the quantities at the beginning and end of each leg (i.e., furthest from the plume).

20 4) Method 4 (M4) - same as M3, but with fixed backgrounds of org $=0.33 \mu \mathrm{g} / \mathrm{m}^{3}$ and $\mathrm{CO}=80.5 \mathrm{ppbv}$ subtracted from the mean of plume quantities for each leg.

5) Method 5 (M5) - same as M2 but with backgrounds of org= $=.53 \mu \mathrm{g} / \mathrm{m}^{3}$ and $\mathrm{CO}=87.7 \mathrm{ppbv}$ subtracted from each OA and CO measurement.

The additional calculations not explicitly described are permutations of the linear regression method employing different

25 background values for $\mathrm{CO}(80.5,83,87.7 \mathrm{ppbv})$ and organics $\left(0.33,0.53 \mu \mathrm{g} / \mathrm{m}^{3}\right)$ and either forcing or not forcing the regression through the origin.

Backgrounds of $\mathrm{CO}$ and org were chosen in several different ways that could be considered reasonable. The organic and CO backgrounds of $0.33 \mu \mathrm{g} / \mathrm{m}^{3}$ and $80.5 \mathrm{ppbv}$ were the average values obtained when the G-1 was unambiguously above the boundary layer on the March $13^{\text {th }}$ flight. These values are the lowest values observed during any portion of the flight. The

30 organic and $\mathrm{CO}$ backgrounds of $0.53 \mu \mathrm{g} / \mathrm{m}^{3}$ and $87.7 \mathrm{ppbv}$ were calculated by averaging the data when the G-1 was transitioning between plume transects (i.e., traveling parallel to the wind and spatially removed from the plume) at $500 \mathrm{~m}$. These values represent the lowest values measured at $500 \mathrm{~m}$. The $\mathrm{CO}$ background of $83 \mathrm{ppbv}$ is the average $\mathrm{CO}$ value at $1000 \mathrm{~m}$ when the G-1 was transitioning between plume transects. 
Our general observations on the $\Delta \mathrm{org} / \Delta \mathrm{CO}$ method are as follows:

1) We see very little sensitivity to using different background org and $\mathrm{CO}$ concentrations when using the linear regression method if the regression is not forced through zero. In Figure S1, M1, M2, and M5 return largely the same $\Delta$ org/ $\Delta C O$ values despite using different background values.

5 2) For this data set, subtracting the background values was not necessary, provided the linear regression was not forced through zero.

3) The choice of background values had the largest influence on $\Delta \mathrm{org} / \Delta \mathrm{CO}$ when linear regressions were forced through zero and backgrounds were subtracted.

4) When linear regressions were not forced through zero, the Y intercept was generally not representative of the background

10 CO concentration.

5) Calculations using the arithmetic mean (methods 3,4) were more sensitive than the linear regression method to choices of the background values.

\section{S2 PMF Analysis of AMS data}

Positive Matrix Factorization (PMF) analysis was performed on the high-resolution organic aerosol mass spectra and error

15 matrix that were measured using the HR-ToF-AMS on the G-1. The PFM2 algorithm version 4.2 (Paatero, 1997;Paatero and Tapper, 1994) was used to analyze the matrix and results were visualized and evaluated using the PMF Evaluation Tool described by Ulbrich et al. (Ulbrich et al., 2009). In preparing the data, ions with a signal to noise (S/N) less than 0.75 were removed from the analysis and ions with $\mathrm{S} / \mathrm{N}$ less than two were downweighted by a factor of two. In addition, ions whose signals are based on the $\mathrm{CO}_{2}$ signal $\left(\mathrm{CO}^{+}, \mathrm{H}_{2} \mathrm{O}^{+}, \mathrm{HO}^{+}, \mathrm{O}^{+}\right)$are also downweighted by a factor of two.

20 PMF analysis of this data set was challenging, due the combination of low concentrations of organic aerosol, fast sampling required for aircraft operations, and the often small changes in aerosol concentrations across the flight domain. PMF analysis on a data from a single flight often (though not always) resulted in a failure to resolve factors that are described in the literature (e.g., HOA, IEPOX SOA); instead, we often observes split factors that are largely dominated by a single high $\mathrm{S} / \mathrm{N}^{\text {ion }}\left(\mathrm{CHO}^{+}\right.$, $\mathrm{CO}_{2}{ }^{+}, \mathrm{C}_{2} \mathrm{H}_{3} \mathrm{O}^{+}$). Therefore, data from all flights during the wet season was combined into a single matrix and analyzed together.

25 We chose a five factor solution to the combined matrix. However, three of the five factors co-varied closely in time and had mass spectral profiles that were dominated by a single ion $\left(\mathrm{CHO}^{+}, \mathrm{C}_{2} \mathrm{H}_{3} \mathrm{O}^{+}\right.$, and $\left.\mathrm{CO}_{2}{ }^{+}\right)$so they were recombined into a single factor, which we label OOA. In separate experiments, we downweighted these three ion signals by factors of 2-10 in an attempt to minimize the splitting of the OOA factor, but were unsuccessful. The spectra of the resultant three factors (after recombining) are shown in Figure S2. We label factors based on comparison to similar literature spectra and on the basis of their

30 correlation with other independently measured species. As shown in Figure 6 in the main text, the OOA factor correlates well with ozone, a known secondary species, while the HOA factor correlates well with $\mathrm{CO}$, a known primary anthropogenic emission. These relationships have been described in previous literature studies and the mass spectra of our OOA and HOA 
factors also compares well with literature spectra for OOA and HOA (Zhang et al., 2005;Zhang et al., 2011;Ng et al., 2010). We label the final factor as the IEPOX SOA factor that is widely reported in the literature and believed to represent SOA formed from the heterogeneous uptake of isoprene epoxydiols onto pre-existing aerosol (Hu et al., 2015;Robinson et al., 2011; Lin et al., 2012). Our assignment is based on comparison with the factor mass spectral profile with those in the literature

5 (Hu et al., 2015).

Our choice of the five factor solution were based on several considerations. First, solutions with fewer factors failed to separate the HOA and the IEPOX SOA factors, which are well described in the literature and were reasonably expected to be present in the data. Second, as previously mentioned, solutions with either three factors clearly showed evidence of factor splitting. The mass spectra of the split factors were dominated by three major ions $\left(\mathrm{CHO}^{+}, \mathrm{CO}_{2}{ }^{+}, \mathrm{C}_{2} \mathrm{H}_{3} \mathrm{O}^{+}\right)$with little signal through the

10 rest of the spectra. These factors are unlikely to represent some real aerosol component, as no known species produce such simple spectra. Furthermore, the individual split factors did not correlate as well with ozone measurement as well as the combined factors. The mathematical reason for the factor splitting is clear; aerosol loading is low, the AMS is sampling at a relatively fast rate (13 s averaging time), and the AMS spectra are dominated by a relatively small number of high S/N ions. Finally, various measurements of the residuals continue to significantly decrease in moving to higher number of factors. For

15 example, $\mathrm{Q} / \mathrm{Q}_{\exp }$ decreases from 0.31 to 0.24 and the fraction of the unexplained variance in aerosol mass decreases from $5 \%$ to $0.1 \%$ in moving from the one to the five factor solution. $\mathrm{Q} / \mathrm{Q}_{\exp }$ only reaches the calculated minimum $\mathrm{Q}$ for the five factor solution.

\section{References}

20 Hu, W. W., Campuzano-Jost, P., Palm, B. B., Day, D. A., Ortega, A. M., Hayes, P. L., Krechmer, J. E., Chen, Q., Kuwata, M., Liu, Y. J., de Sa, S. S., McKinney, K., Martin, S. T., Hu, M., Budisulistiorini, S. H., Riva, M., Surratt, J. D., St Clair, J. M., Isaacman-Van Wertz, G., Yee, L. D., Goldstein, A. H., Carbone, S., Brito, J., Artaxo, P., de Gouw, J. A., Koss, A., Wisthaler, A., Mikoviny, T., Karl, T., Kaser, L., Jud, W., Hansel, A., Docherty, K. S., Alexander, M. L., Robinson, N. H., Coe, H., Allan, J. D., Canagaratna, M. R., Paulot, F., and Jimenez, J. L.: Characterization of a real-time tracer for isoprene epoxydiols-derived secondary organic aerosol (IEPOX-SOA) from aerosol mass spectrometer measurements, Atmos. Chem. Phys., 15, 11807-11833, 10.5194/acp-15-11807-2015, 2015.

Lin, Y. H., Zhang, Z., Docherty, K. S., Zhang, H., Budisulistiorini, S. H., Rubitschun, C. L., Shaw, S. L., Knipping, E. M., Edgerton, E. S., Kleindienst, T. E., Gold, A., and Surratt, J. D.: Isoprene epoxydiols as precursors to secondary organic aerosol formation: acid-catalyzed reactive uptake studies with authentic compounds, Environ Sci Technol, 46, 250-258, 10.1021/es202554c, 2012.

Ng, N. L., Canagaratna, M. R., Zhang, Q., Jimenez, J. L., Tian, J., Ulbrich, I. M., Kroll, J. H., Docherty, K. S., Chhabra, P. S., Bahreini, R., Murphy, S. M., Seinfeld, J. H., Hildebrandt, L., Donahue, N. M., DeCarlo, P. F., Lanz, V. A., Prevot, A. S. H., Dinar, E., Rudich, Y., and Worsnop, D. R.: Organic aerosol components observed in Northern Hemispheric datasets from Aerosol Mass Spectrometry, Atmos. Chem. Phys., 10, 4625-4641, 10.5194/acp-10-4625-2010, 2010.

Paatero, P., and Tapper, U.: Positive matrix factorization: A non-negative factor model with optimal utilization of error estimates of data values, Environmetrics, 5, 111-126, 10.1002/env.3170050203, 1994.

Paatero, P.: Least squares formulation of robust non-negative factor analysis, Chemometrics and Intelligent Laboratory Systems, 37, 23-35, 
Robinson, N. H., Hamilton, J. F., Allan, J. D., Langford, B., Oram, D. E., Chen, Q., Docherty, K., Farmer, D. K., Jimenez, J. L., Ward, M. W., Hewitt, C. N., Barley, M. H., Jenkin, M. E., Rickard, A. R., Martin, S. T., McFiggans, G., and Coe, H.: Evidence for a significant proportion of Secondary Organic Aerosol from isoprene above a maritime tropical forest, Atmos. Chem. Phys., 11, 1039-1050, 10.5194/acp5 11-1039-2011, 2011.

Ulbrich, I. M., Canagaratna, M. R., Zhang, Q., Worsnop, D. R., and Jimenez, J. L.: Interpretation of organic components from Positive Matrix Factorization of aerosol mass spectrometric data, Atmos. Chem. Phys., 9, 2891-2918, 10.5194/acp-9-2891-2009, 2009.

Zhang, Q., Alfarra, M. R., Worsnop, D. R., Allan, J. D., Coe, H., Canagaratna, M. R., and Jimenez, J. L.: Deconvolution and quantification 10 of hydrocarbon-like and oxygenated organic aerosols based on aerosol mass spectrometry, Environ Sci Technol, 39, 4938-4952, 2005.

Zhang, Q., Jimenez, J. L., Canagaratna, M. R., Ulbrich, I. M., Ng, N. L., Worsnop, D. R., and Sun, Y.: Understanding atmospheric organic aerosols via factor analysis of aerosol mass spectrometry: a review, Anal Bioanal Chem, 401, 3045-3067, 10.1007/s00216-011-5355-y, 2011. 


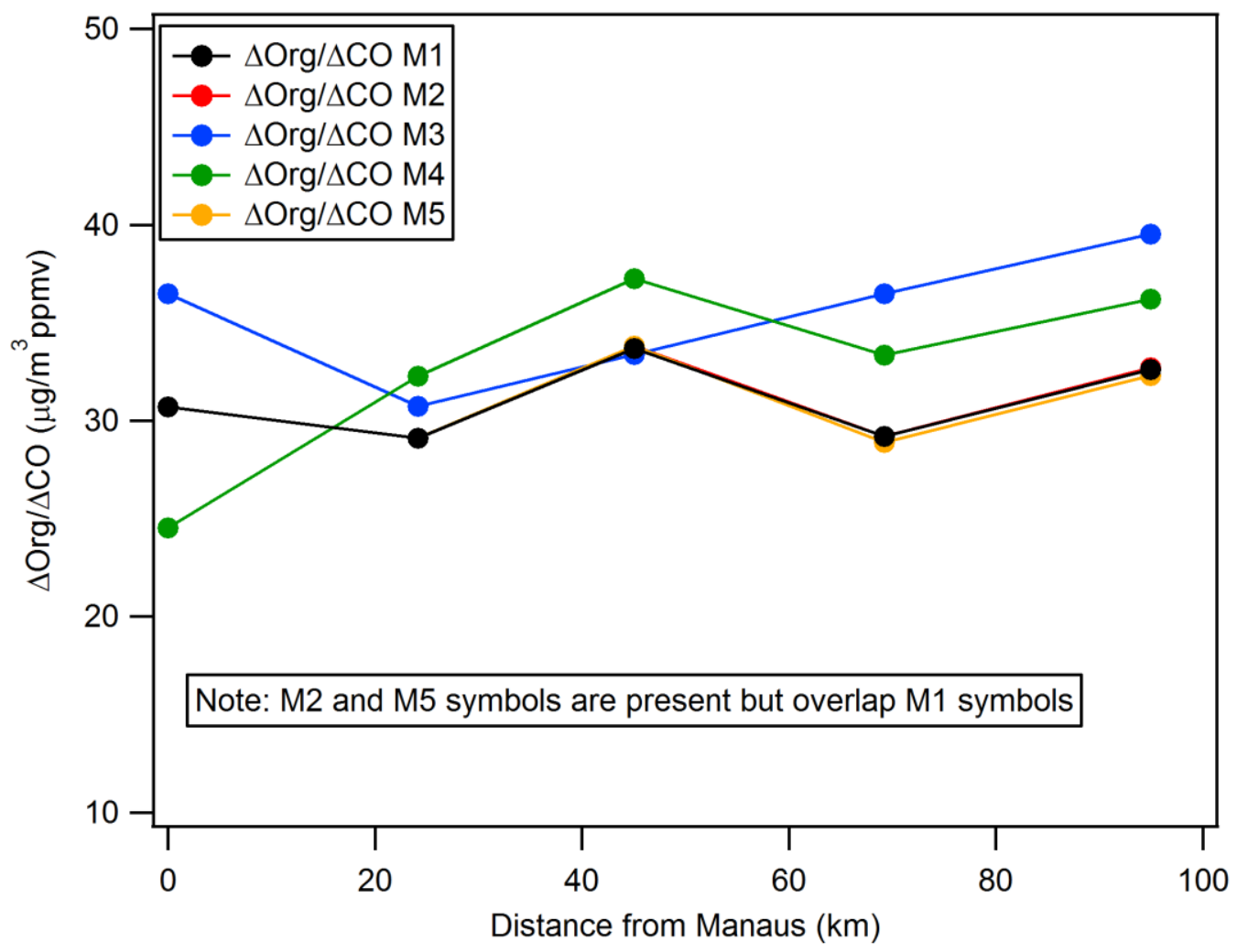

Figure S1. Evaluation of $\Delta \mathrm{org} / \Delta \mathrm{CO}$ as a function of Manaus plume age using several different methods. A total of 16 different methods were used to calculate $\Delta \circ \mathrm{rg} / \Delta \mathrm{CO}$, with a subset shown here. Note that no method shows a significant change in $\Delta$ org/ $\Delta C O$ 5 with plume age. The different methods for calculating $\Delta$ org/ $\Delta C O$ are describe in the text. 


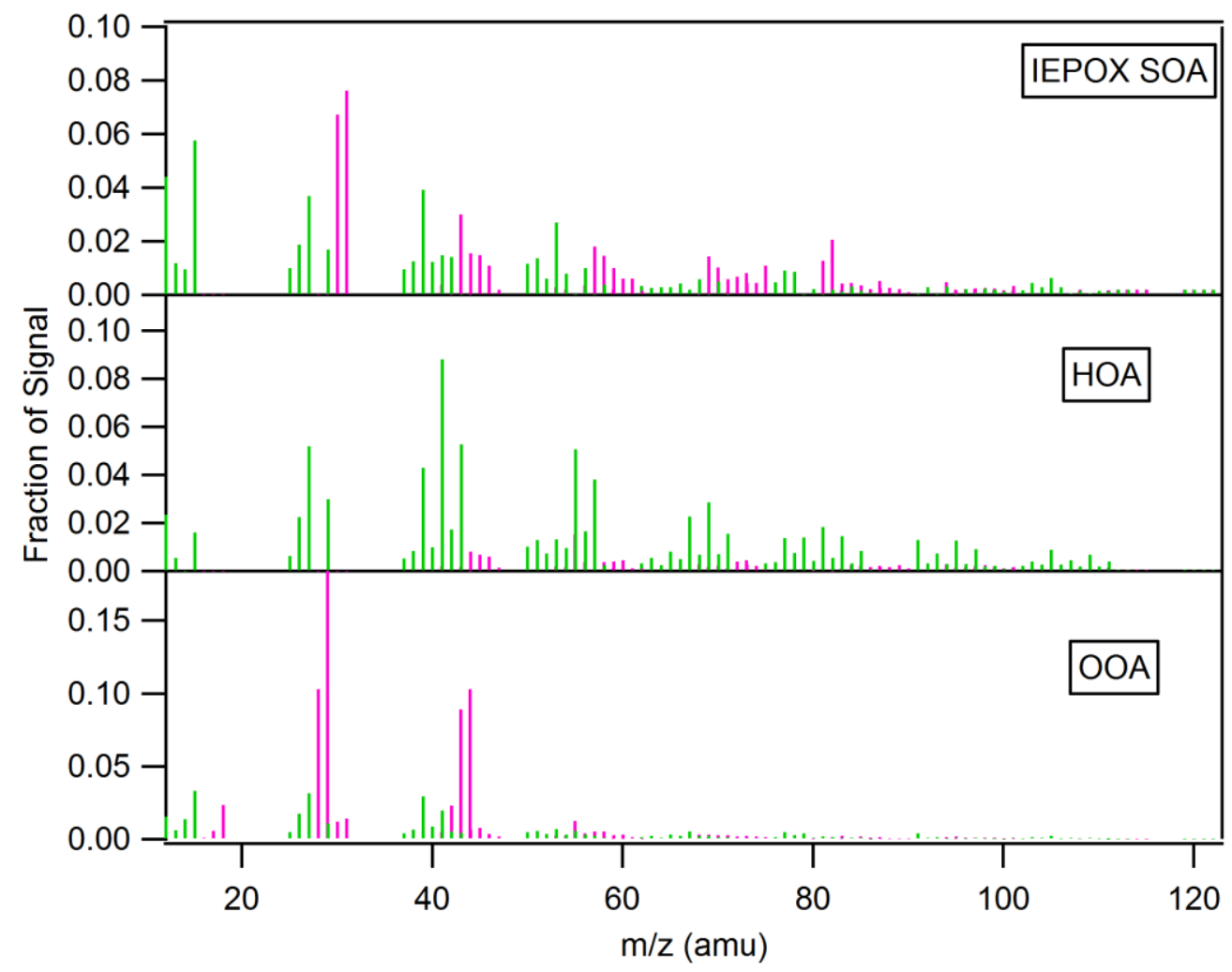

Figure S2. PMF spectra for the three factors reported in the manuscript. The analysis used high resolution AMS data, but the signals are represented as sticks for clarity. Sticks are colored by the chemical composition of the ion; ions in the $\mathrm{C}_{\mathrm{x}} \mathrm{H}_{\mathrm{y}}$ family are green and those in the $\mathrm{C}_{\mathrm{x}} \mathrm{H}_{\mathrm{y}} \mathrm{O}_{\mathrm{z}}$ family are pink. 